\title{
Exploring the Usage of Social Networking Websites: Perceptions and Opin- ions of Romanian University Students
}

\author{
Dragoş Daniel IORDACHE ${ }^{1}$, Vincentas LAMANAUSKAS ${ }^{2}$ \\ ${ }^{1}$ National Institute for Research and Development in Informatics - ICI Bucharest \\ ${ }^{2}$ Siauliai University \\ iordache@ici.ro,v.lamanauskas@ef.su.1t
}

Social networking websites (SNWS) have become a popular virtual meeting place allowing users to voluntarily post personal information, send and receive message, stay connected online with their offline friends and new online friends, or share photos, videos, bookmarks, blogs, private messages and join groups. People are spending ample amount of time on social networking websites such as You Tube, Facebook, Google+, LinkedIn, Facebook, Twitter, Hi5 etc., and this high usage has also brought changes in the way people behave. These social networking websites present a variety of features for their users to facilitate socialization. This paper presents the results of a study aiming to identify the Romanian student opinions regarding SNWs. The main findings of this study are: the most frequently visited and most popular social networks among Romanian student are You Tube and Facebook; the majority of the respondents use social networking websites a few times a day; only a small part of the respondents know how social networking websites use published and other type of information; the usage of SNWs is related with the usage of computers and internet. Also the most important functions of SNWs for Romanian student are: communication (including communication in interest groups), learning and exchanging information, exchanging photo, video, friend search and texting.

Keywords: Social Networking Websites, Survey, University Students

$\mathbf{1}^{1}$ Introduction

Nowadays, social network websites are increasingly used by a diverse group of people. Recent data indicate that $65 \%$ of Internet using adults in the United States has a profile on at least one SNW [13].

Researchers have argued that social network websites (SNWs) reduce the transaction costs of maintaining a larger (and potentially more diverse) social network, enable individuals to engage in relationship, maintenance activities with their connections, and facilitate the extraction of resources from the network [3], [4], [11].

As social network sites (SNWs) have been shown to connect individuals to people with whom they have a previously established offline connection [9], as well as to connections of different degrees of relational closeness [5], it is likely that people turn to SNWs as an efficient way to tap these connections for information-seeking purposes.

These sites can be oriented towards workrelated contexts (e.g., LinkedIn.com), roman- tic relationship initiation (the original goal of Friendster.com), connecting those with shared interests such as music or politics (e.g., MySpace.com), or the college student population [4].

In [2] the author divided SNW users into five use clusters based on how they described their site behaviors (e.g. Lurkers, Socializers, Debaters, Sporadics and Advanced) and found difference in loneliness and bridging social capital between those groups. The heterogeneity of motivation to use means that people have different outcomes resulting from their participation.

Recent research has begun to identify user characteristics - such as cultural differences [20] - that significantly predict question and answer behavior on SNWs as well as factors that influence characteristics of responses (such as quality and quantity) to informationseeking activities in these social online contexts [16].

Informal systems can include student-created communication channels such as websites, 
email lists, or online discussion forums where students gather for other purposes, like social interaction [10]. Information and communication technologies (ICTs) are becoming a ubiquitous component of learning. ICTs ranging from traditional course management systems to more interactive tools, such as student response systems and classroom backchannels, now provide additional opportunities to support the learning process, and learning experts are examining the potential of new media tools to transform educational practices [6].

Communication technologies are often seen as reducing coordination costs required by the tasks of organizing [17]. The Internet has been linked both to increases and decreases in social capital. In [14], for example, argued that Internet use detracts from face-to-face time with others, which might diminish an individual's social capital.

SNW offer different applications, designs, and contents for their users. How these websites make themselves different from each other, and how they persuade users to join their social network or how these enhance the quality of their image in users' mind are the questions that need to be addressed. In a recent study [7] the author developed a questionnaire to ascertain how Lithuanian university students use social networking websites, what opinion they have about various social networking websites, and what they know about them. The data collected in Lithuania was further analyzed to identify dimensions of the perceived usefulness [8] as well as negative aspects related to their usage [1].

The results of this study show that university students highly value social networking websites. SNW can be useful for communication and leisure time, also social and information getting needs. SNW is a good way for finding friends, communicating with them. It is obvious that SNW can be effectively used for acquiring knowledge and getting the newest information from the whole world.

The research purpose of this work is to ascertain how Romanian university students use social networking websites, what opinion they have about various social networking websites. The main research questions are:

- What social networking websites do students know and use most frequently?

- What social networking website functions do students use and why?

- Do students like social networking websites and why?

- What do students know about how social networking websites use published personal and other type of information?

- What is students' attitude to opportunities provided by social networking websites?

\section{Method and Procedure 2.1 Participants}

In order to find out Romanian students' opinion about social networks a study was carried on in 2012. 172 university students participated. From them, 130 are from the University of Bucharest and 42 from the Academy of Economic Studies in Bucharest. According to sex, $140 / 81.4 \%$ of girls and $32 / 18.6 \% \%$ of boys participated in the research. According to the course level, $96 / 55.8 \%$ of the students were enrolled in a Master degree and $76 / 44.2 \%$ where enrolled in a Bachelor degree.

\subsection{Instrument}

This research is based on the questionnaire used in [7]. The questionnaire comprises 16 questions. From these, 3 questions are allotted to establish the characteristics of the respondents, 5 open type questions. The 6th question was assigned to evaluate the frequency of social networking website usage. 23 main networking websites are presented in the list. The 8th question was allotted to evaluate the functions of social networking websites (e.g., communication, advertisement, friend search, information exchange and so on). Also, 26 various type statements about social networking websites were presented and the respondents were asked to evaluate them applying the interval Likert scale (from "Completely agree" to "Completely disagree"). 


\subsection{Statistical Data Analysis}

In order to analyze research data, measures of descriptive statistics are applied (absolute and relative frequencies, standard deviations). The statistical analysis software SSPS 15 for Windows was used for data processing.

\section{Results}

\subsection{The Frequency of Using and the Time Spent on Internet}

Regarding the question How often do you use the internet? analysis showed, that even $142 / 82.6 \%$ of the students use the internet a few times a day, $23 / 13.4 \%$ - once a day, only $4 / 2.3 \%$ of the students a few times a week and none of the students every two weeks or less.

It is useful to know, how much time on average students spend on the internet during one visit (Table 1).

Table 1. Time spent on the internet (N/\%)

\begin{tabular}{|l|r|r|}
\hline Time & \multicolumn{1}{|c|}{ N } & \multicolumn{1}{c|}{$\%$} \\
\hline Less than 10 min. & 7 & 4.1 \\
\hline From10 to 30 min. & 25 & 14.5 \\
\hline From 30 min. to 1h. & 46 & 26.7 \\
\hline From 1 to 2h. & 41 & 23.8 \\
\hline From 2 to 3 h. & 24 & 14.0 \\
\hline More than 3 h. & 29 & 16.9 \\
\hline Total & 172 & 100.00 \\
\hline
\end{tabular}

It appears that $46 / 26.7 \%$ of the respondents spend from half an hour to one hour on the Internet during one visit, $41 / 23.8 \%$ - from one hour to 2 hour and $25 / 14.5 \%$ - from ten to thirty minutes. $29 / 16.9 \%$ of the respondents spend more than three hours on the internet. As the majority of students use the Internet a few times a day, it means, that the youth spend quite a lot of their time on the internet networking sites.

\subsection{Frequency of using SNWs}

The researchers were interested, how often and how much time students being on the internet visit social networking websites.
Table 2. Frequency of visiting SNWs

\begin{tabular}{|l|l|c|}
\hline Visiting frequency & $\mathbf{N}$ & $\mathbf{\%}$ \\
\hline A few times a day & 71 & 41.3 \\
\hline Once a day & 51 & 29.7 \\
\hline 3-5 times a week & 9 & 5.2 \\
\hline 1-2 times a week & 30 & 17.4 \\
\hline Every two weeks & 3 & 1.7 \\
\hline Less & 8 & 4.7 \\
\hline Total & 172 & 100 \\
\hline
\end{tabular}

The analysis of the question How often do you visit internet social networking websites? showed, that $71 / 41.3 \%$ of the respondents at least a few times a day visit internet social networking websites, $51 / 29.7 \%$ - at least once a day. Only a small part is visiting the internet a few times a week or less (Table 2). To the question How much time on average do you spend on the internet social networking websites during one visit? 60/34.9\% of the respondents asserted, that from ten minutes to half an hour, and 34/19.8\% - less than ten minutes.

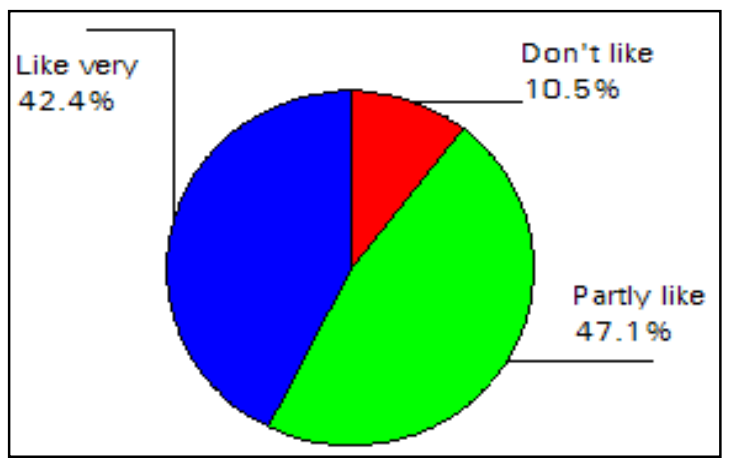

Fig. 1. Attitude to social networking websites

Comparing with the time spent on the internet in general, it can be thought, that students use the internet not only because of social networking websites.

The students were asked, whether they like social networking websites.

Data analysis showed, that the biggest part of the respondents $(81 / 47.1 \%)$ partly like social networking websites and only $18 / 10.5 \%$ don't like (Figure 1). Whilst 73/42.4\% like social networking websites very much and willingly use them. 
3.3 Usage of Social Networking Websites A total of 24 social networking websites known for researchers were presented in the questionnaire, and the respondents were asked how often they participate in them. 10 social networking websites, which Romanian students visit, are presented in Table 3.

Table 3. Students about participation in social networking websites: usage frequency (N/\%)

\begin{tabular}{|l|l|l|l|l|l|l|l|l|l|l|l|}
\hline $\begin{array}{l}\text { Social networking } \\
\text { websites }\end{array}$ & \multicolumn{2}{l|}{ Daily } & \multicolumn{2}{l|}{ Once a week } & \multicolumn{2}{l|}{ Once a month } & \multicolumn{2}{l|}{$\begin{array}{l}\text { Less than } \\
\text { once a month }\end{array}$} & \multicolumn{2}{l|}{ Don't use } \\
\hline You Tube & $\begin{array}{l}12 \\
5\end{array}$ & $72.7 \%$ & 34 & $19.8 \%$ & 5 & $2.9 \%$ & 3 & $1.7 \%$ & 5 & $2.9 \%$ \\
& 12 & $73.8 \%$ & 22 & $12.8 \%$ & 3 & $1.7 \%$ & 4 & $2.3 \%$ & 16 & $9.3 \%$ \\
\hline Facebook & 7 & & & & & & & & & \\
& 76 & $44.2 \%$ & 17 & $9.9 \%$ & 12 & 7.0 & 11 & 6.4 & 56 & $32.6 \%$ \\
\hline Google+ & 7 & $4.1 \%$ & 6 & $3.5 \%$ & 13 & 7.6 & 13 & 7.6 & 133 & $77.3 \%$ \\
\hline LinkedIn & 1 & $0.6 \%$ & 10 & $5.8 \%$ & 12 & $7 \%$ & 8 & $4.7 \%$ & 141 & $82 \%$ \\
\hline Windows Live Profile & 1 & $0.6 \%$ & 6 & $3.5 \%$ & 9 & $5.2 \%$ & 5 & $2.9 \%$ & 151 & $87.8 \%$ \\
\hline Vimeo & 1 & $0.6 \%$ & 3 & $1.7 \%$ & 8 & $4.7 \%$ & 14 & $8.1 \%$ & 146 & $84.9 \%$ \\
\hline Twitter & 2 & $1.2 \%$ & 4 & $2.3 \%$ & 4 & $2.3 \%$ & 8 & $4.7 \%$ & 154 & $89.5 \%$ \\
\hline Hi5 & 5 & $2.9 \%$ & 1 & $0.6 \%$ & 1 & $0.6 \%$ & 5 & $2.9 \%$ & 160 & $93 \%$ \\
\hline OpenID & 2 & $1.2 \%$ & 0 & $0 \%$ & 7 & $4.1 \%$ & 7 & $4.1 \%$ & 156 & $90.7 \%$ \\
\hline Dailymotion & & & & & & & & & & \\
\hline
\end{tabular}

The most visited internet networking websites are: You Tube, Facebook, Google+, and LinkedIn. All other social networking websites are visited rarely and not all respondents participate, however, there isn't a SNW not known and not participated by at least a few respondents. In these internet portals every consumer can create his profile, make friends, and communicate in interest groups and so on.

\subsection{Social Networking Website Functions}

The respondents were asked to evaluate social networking website functions according to their importance to them. 14 functions were presented and were asked to evaluate using 5 point ranking scale from 1 - completely unimportant to 5 - very important. According to the importance, functions are presented in Table 4.

The most important functions are: communication $($ mean $=3.90, \mathrm{SD}=1.18)$, learning and information exchange (mean $=3.84$, SD $=1.19$ ), exchanging photos, videos and so on (mean $=3.23, \mathrm{SD}=1.21)$ and searching friends $($ mean $=3.15, \mathrm{SD}=1.31)$.

Among students, is also popular texting (mean $=2.98, \mathrm{SD}=1.26)$, spending leisure time on the internet $($ mean $=2.97, \mathrm{SD}=1.22)$ and advertising $($ mean $=2.94, \mathrm{SD}=1.41)$. Not a big part of the respondents admire "spying" each other (mean $=2.97, \mathrm{SD}=$ 1.22), evaluation or „Read.Watch.Listen“ technology (mean $=2.40, \mathrm{SD}=1.30)$ and posting link using mobile phone (mean = 2.34, $\mathrm{SD}=1.30)$. Games (on-line) $($ mean $=$ $2.02, \mathrm{SD}=1.15)$ and flirt on the social networking websites $($ mean $=1.98, \mathrm{SD}=1.20)$ get the lowest evaluation.

Table 4. Students' opinions regarding the importance of social networking website functions $(\mathrm{N}=172)$

\begin{tabular}{|c|c|c|c|}
\hline \multicolumn{2}{|r|}{ Functions } & Mean & SD \\
\hline 1 & Communication & 3.90 & 1.18 \\
\hline 2 & $\begin{array}{l}\text { Learning and exchanging } \\
\text { information }\end{array}$ & 3.84 & 1.19 \\
\hline 3 & $\begin{array}{l}\text { Exchanging photo, video } \\
\text { and so on. }\end{array}$ & 3.23 & 1.21 \\
\hline 4 & Friend search & 3.15 & 1.31 \\
\hline 5 & Texting & 2.98 & 1.26 \\
\hline 6 & Spending leisure time & 2.97 & 1.22 \\
\hline 7 & Advertisement & 2.94 & 1.41 \\
\hline 8 & Link posting from Internet & 2.80 & 1.28 \\
\hline 9 & $\begin{array}{l}\text { Video conversations in } \\
\text { groups }\end{array}$ & 2.43 & 1.30 \\
\hline 10 & „Spying“ & 2.40 & 1.29 \\
\hline 11 & $\begin{array}{lr}\text { Evaluation } & \text { or } \\
\text { „Read.Watch.Listen“ } & \text { tech- } \\
\text { nology } & \end{array}$ & 2.40 & 1.30 \\
\hline 12 & $\begin{array}{l}\text { Link posting using mobile } \\
\text { phone }\end{array}$ & 2.34 & 1.30 \\
\hline 13 & Games (on-line) & 2.02 & 1.15 \\
\hline 14 & Flirting & 1.98 & 1.20 \\
\hline
\end{tabular}


3.5 Personal Information Used By Social Networking Sites

Respondents were asked if they know, how social networking websites use published personal or other type of information.

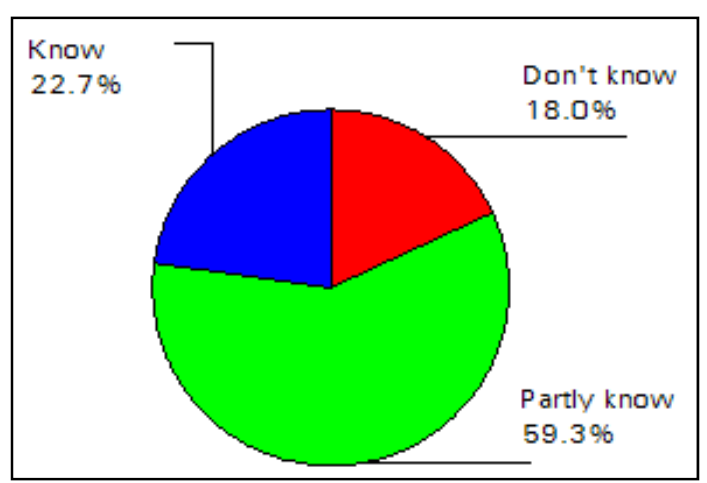

Fig. 2. The level of knowledge about how SNW use published personal or other type of information

The answers showed, that only $22.7 \%$ of the respondents know, the rest $59.3 \%$ - partly know and even $18 \%$ don't know, where their information is used (Figure 2).

It was interesting to know the respondents'opinion about people, who use social networking websites. The participants were asked to evaluate 4 statements about people tending to use social networks using 5 point ranking scale from 1 - completely disagree to 5 - completely agree. The measures of cen- tral tendency and variation are presented in Table 5.

Table 5. Students about people tending to use social networking websites.

\begin{tabular}{|l|l|l|l|}
\hline \multicolumn{2}{|c|}{ People tending to use SNW are: } & Mean & SD \\
\hline 1 & Enjoying socializing & 4.20 & 0.77 \\
\hline 2 & Enjoying new technologies & 4.15 & 0.73 \\
\hline 3 & Searching for novelties & 3.56 & 0.80 \\
\hline 4 & $\begin{array}{l}\text { Having communication diffi- } \\
\text { culties in real life }\end{array}$ & 3.20 & 1.12 \\
\hline
\end{tabular}

\subsection{Students Opinions about Social Net- working Websites}

Social network reveals the activity of the participants, their sociality, because the main information in them is, what the consumer wrote, what his mood was, who he started dating, what photos he installed, what commentaries he wrote, who he joined and so on. 26 statements were presented in the questionnaire about social networks and respondents were asked to evaluate them.

Also, participants were asked to evaluate the statements about social networks using a 5points ranking scale from 1 (completely disagree) to 5 (completely agree). The measures of central tendency and variation are presented, in a decreasing order of mean values, in Table 6.

Table 6. Opinion about social networking websites

\begin{tabular}{|l|l|l|l|}
\hline \multicolumn{2}{|c|}{ Statements about SNW } & Mean & SD \\
\hline 1 & Communication in virtual space will never substitute direct peoples' relations & 4.14 & 0.97 \\
\hline 2 & SN websites is a good possibility to find out various news & 4.02 & 0.83 \\
\hline 3 & SN websites earn a lot of money using free personal information & 3.98 & 0.85 \\
\hline 4 & SN websites is a very good means for communication & 3.89 & 0.87 \\
\hline 5 & One can find a lot of useful information in SN websites & 3.88 & 0.76 \\
\hline 6 & $\begin{array}{l}\text { Most people belonging to SN websites don't know, who they share information } \\
\text { with about themselves, their hobbies and life }\end{array}$ & 3.81 & 0.87 \\
\hline 7 & SN websites distract people from reality & 3.77 & 0.94 \\
\hline 8 & SN websites is a good means for self-advertising & 3.76 & 0.83 \\
\hline 9 & SN websites give national and international knowledge & 3.72 & 0.80 \\
\hline 10 & SN websites make negative influence on learning marks and ability to concentrate & 3.70 & 0.92 \\
\hline 11 & $\begin{array}{l}\text { Information conveyed by SN websites can have negative influence on teenagers' } \\
\text { behaviour and health }\end{array}$ & 3.68 & 0.86 \\
\hline 12 & Constant staying in virtual environment causes damage to person's socialization & 3.67 & 1.00 \\
\hline 13 & SN websites help to make friends & 3.66 & 0.91 \\
\hline 14 & Staying in SN websites is more fashionable than useful & 3.64 & 0.97 \\
\hline 15 & This is a good opportunity to learn, improve, communicate with the whole world & 3.60 & 1.01 \\
\hline
\end{tabular}




\begin{tabular}{|l|l|l|l|}
\hline & without going out from home & & \\
\hline 16 & SN websites is a good means for relaxation & 3.59 & 0.91 \\
\hline 17 & SN websites is a good means for spending your leisure time & 3.41 & 1.01 \\
\hline 18 & People taking part in SN websites contribute to ICT development & 3.39 & 0.75 \\
\hline 19 & SN websites is a reliable computer device & 3.39 & 0.77 \\
\hline 20 & Communication in virtual space gives bigger opportunities & 3.36 & 0.89 \\
\hline 21 & SN websites is a good thing for those, who are not aware what privacy is & 3.31 & 1.04 \\
\hline 22 & SN websites save time, allow acting more effectively & 3.31 & 0.89 \\
\hline 23 & SN websites encourage people estrangement & 3.27 & 0.88 \\
\hline 24 & SN websites dehumanise society & 3.19 & 0.98 \\
\hline 25 & People of lower education mostly use SN websites & 3.03 & 1.06 \\
\hline 26 & SN websites can encourage the youth for suicide & 2.85 & 1.03 \\
\hline
\end{tabular}

The respondents are firmly convinced, that communication in virtual space will never substitute direct people's relations (mean = $4.14, \mathrm{SD}=0.97$ ). In their opinion, $\mathrm{SNW}$ is a perfect possibility to find out various news (mean $=4.02, \mathrm{SD}=0.83), \mathrm{SNW}$ earn a lot of money using free personal information (mean $=3.98, \mathrm{SD}=0.85$ ), and are very good means of communication $($ mean $=3.89, \mathrm{SD}=0.87)$. Negative social networking websites'traits are accentuated as well: the majority of people belonging to SNW don't know, who with they share information about themselves, their hobbies and their life (mean $=3.81$, SD $=0.87$ ), $\mathrm{SN}$ websites distract people from reality (mean $=3.77, \mathrm{SD}=0.94)$ and $\mathrm{SNW}$ make a negative influence on learning marks and on the ability to concentrate (mean = $3.70, \mathrm{SD}=0.92$ ). However, students don't agree, that mostly lower education people use SNW (mean $=3.03, \mathrm{SD}=1.06$ ) and doubt whether SNW can encourage the youth for suicide $($ mean $=2.85, \mathrm{SD}=1.03)$.

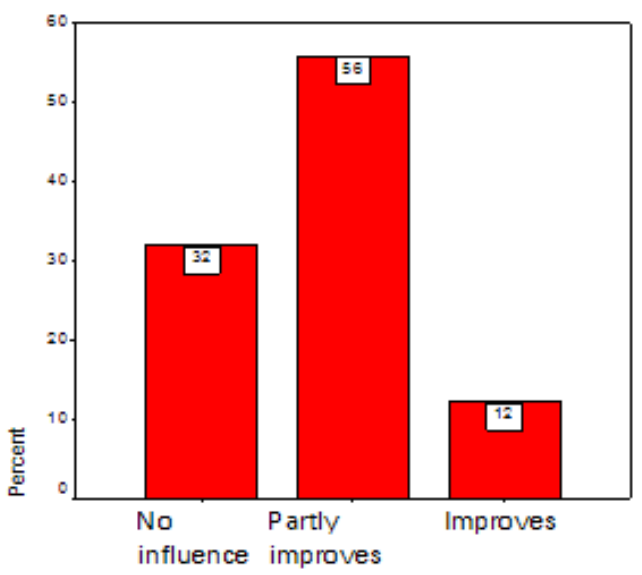

Fig. 3. The influence of SN websites usage in improving communication abilities
Another question refers to the relation between usage of SN websites and improving the communication abilities of the respondents.

The answers showed, that only $12 \%$ of the respondents are firmly convinced that the usage of SN websites improve their communication abilities (Figure 3). The largest percent $-56 \%$ consider that $\mathrm{SN}$ websites only partly improves communication abilities, while $32 \%$ consider that $\mathrm{SN}$ websites usage has no influence on their communication abilities

\section{Discussions}

The usage of such networking websites is directly related with the usage of computers and Internet [7]. The research carried out by the authors showed that Romanian students have little knowledge about how personal information is used in social networking websites. Online privacy affects aspects such as the obtaining, distribution or the nonauthorized use of personal information. This issue of privacy/ security has raised an important issue by highlighting consumer distrust as to how their personal data are being gathered and processed. The quantitative importance of this issue is shown in [18], who points out that the protection of privacy is the greatest concern of Internet users.

Social networking websites are usually devoid of online transactions, but still users are concerned about privacy and security. They need to protect their personal and sensitive information. For this purpose, these websites should strive for the best and sophisticated security system. In order to maintain the quality, management should conduct online 
"site improvement" surveys or should start opinion blogs.

Most of the Romanian students intensively use the internet and spend from one hour to two, daily navigating. Almost a half of the respondents appreciated very positively social networking websites, they like them. Even those who don't like social networking websites, periodically visit them. Also, majority of students consider that SN websites partly improves communication abilities, while $32 \%$ consider that $\mathrm{SN}$ websites usage has no influence on their communication abilities.

\section{Conclusion}

Social networking websites have become a significant component of people's daily lives and are built upon the concept of traditional social networks, which connect users to new people having common interests. The most frequently visited and most popular social networks among Romanian student are: You Tube, Facebook, and Google+.

The most important functions of SNWs for Romanian student are: communication (including communication in interest groups), learning and exchanging information, exchanging photo, video, friend search and texting. Certain sex differences have been noticed valuing social networking websites.

Data analysis shows that the majority of the respondents use the internet a few times a day and more than a half of them visit social networking websites a few times a day as well. Only a small part of the respondents haven' $t$ created their personal profile in social networking websites. It is obvious, that the usage of the internet and visiting social networking websites are closely and directly related things.

Only a small part of the respondents know how social networking websites use published and other type of information. Although SNWs were appreciated as an excellent means of communication, a perfect opportunity for finding out various news, for making friends, students are firmly convinced, that communication in virtual space will never substitute direct people's relations
[7]. It can be concluded that by adopting a customer-oriented strategy, social networking website developers should devote significant attention to develop safety standards as well as user-friendly navigation tools, as these measures can enhance trust as well as increase the numbers of users.

\section{References}

[1] A. Balog, C. Pribeanu, V. Lamanauskas, V. Slekiene, "A multidimensional model for the exploration of negative effects of social networking websites as perceived by students". Journal of Baltic Science Education, 12(3), 2013, pp. 378-388.

[2] P.B. Brandtzaeg, "Social networking sites: Their users and social implications - a longitudinal study", Journal of Computer-Mediated Communication, 17, 2012, pp. 467-488.

[3] J.S. Donath, "Signals in social supernets", Journal of Computer-Mediated Communication, 13, 2007, pp 231-251.

[4] N. Ellison, J. Vitak, R. Gray, C. Lampe, B. Brooks, Cultivating Social Resources on Facebook: Signals of Relational Investment and their Role in Social Capital Processes iCS-OII 2011 "A Decade in Internet Time" Symposium. , Oxford, UK, 2011.

[5] E. Gilbert, K. Karahalios, Predicting tie strength with social media, Proceedings of the 27th international conference on Human factors in computing systems, 2009, ACM, Boston, MA, USA.

[6] C. Greenhow, B. Robelia, Informal learning and identity formation in online social networks. Learning, Media and Technology, 34, 2009, pp.119-140.

[7] V. Lamanauskas, V. Slekiene, L. Raguliene, Usage of social networking websites: Lithuanian university students' position. Problems of Education in the 21th Century, 45, 2012,pp. 27-39.

[8] V. Lamanauskas, V. Slekiene, A. Balog, C. Pribeanu, Exploring the usefulness of social networking websites: a multidimensional model. Studies in Informatics and Control, 22(2), 2013, pp. 175-184.

[9] C. Lampe, N. Ellison, C. Steinfield, A 
Face(book) in the Crowd: Social Searching vs. Social Browsing. In ACM Special Interest Group on ComputerSupported Cooperative Work, (Banff, Canada), ACM Press, 2006.

[10] C. Lampe, Y.W. Donghee, J. Vitak, N.B. Ellison, Wash, R. Student use of Facebook for organizing collaborative classroom activities. ComputerSupported Collaborative Learning, 2011, 6:329-347.

[11] C. Lampe, J. Vitak, R. Gray, N. Ellison, Perceptions of Facebook's Value as an Information Source in 30th International Conference on Human Factors in Computing Systems (CHI), (Austin, TX), ACM Press, 2012, pp. 3195-3204.

[12] C. Lampe, J. Vitak, N. Ellison, Users and Nonusers: Interactions between Levels of Facebook Adoption and Social Capital, Understanding People's Practices in Social Networks, San Antonio, TX, USA, 2013, pp. 809-819.

[13] M. Madden, K. Zickuhr, 65\% of Online Adults Use Social Networking Sites, Pew Internet \& American Life Project, Washington, DC, 2011.

[14] N.H. Nie, Sociability, interpersonal relations, and the Internet: Reconciling conflicting findings. American Behavioral
Scientist, 45(3), 2001, pp. 420-35.

[15] R. Putnam, Bowling alone: The collapse and revival of American community. Simon \& Schuster, New York, 2000.

[16] J. Teevan, M.R. Morris, K. Panovich, Factors Affecting Response Quantity, Quality, and Speed for Questions Asked via Social Network Status Messages. in ICWSM - International Conference on Weblogs and Social Media, (Barcelona, Spain), 2011.

[17] J. Thompson, Organizations in action: Social science bases of administrative theory. New York: McGraw-Hill, 1967.

[18] G. Udo, Privacy and security concerns as major barriers for E-commerce: a survey study. Information Management \& Computer Security 9 (4), 2001, pp. 165-174.

[19] D. Williams, On and off the 'Net: Scales for social capital in an online era. Journal of Computer-Mediated Communication, 11, 2006, pp. 593-628.

[20] J. Yang, M.R. Morris, J. Teevan, L. Adamic, M. Ackerman, Culture Matters: A Survey Study of Social Q\&A Behavior, Proc. of ICWSM - International Conference on Weblogs and Social Media, (Barcelona, Spain), 2011.

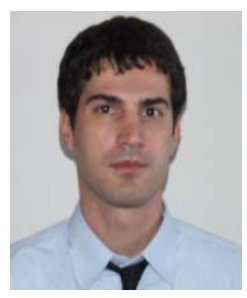

Dragoş Daniel IORDACHE received the $\mathrm{PhD}$ degree in Education Sciences from the University of Bucharest in 2011. Currently he is a scientific researcher at ICI Bucureşti. Dragoş Daniel Iordache is a member of the Romanian HCI group (RoCHI - SIGCHI Romania) and he served as conference reviewer for the last editions of the national conference. His research interests include: usability and pedagogical evaluation of educational systems, usability guidelines, user testing and heuristic evaluation. He is author / co-author of 3 book chapters, 10 journal papers and 20 conference papers.

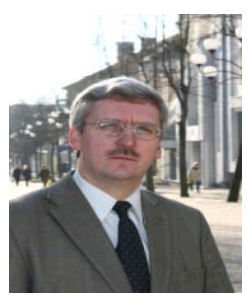

Vincentas LAMANAUSKAS is Professor in Education Sciences, Head of Natural Science Education Research Centre at Siauliai University, Lithuania. His research interests include: comparative educational issues, problems of natural science education in comprehensive school, psycho-physiological aspects of interaction between nature and human being, national and contemporary education management and politics, quality of management. He published more than 450 scientific and methodic articles and 20 methodicdidactic publications in Lithuanian and foreign press. 